\title{
Postoperative EEG in Hemimegalencephaly
}

\author{
Laurent Sheybani $^{\mathrm{a}} \quad$ Christian Korff $^{\mathrm{b}}$ Oliver Maier ${ }^{\mathrm{e}}$ Maria-Isabel Vargas ${ }^{\mathrm{c}}$ \\ Karl Schaller $^{d}$ Margitta Seeck ${ }^{a}$ \\ ${ }^{a}$ Department of Neurology, University Hospital of Geneva, ${ }^{b}$ Pediatric Neurology, Pediatric Specialties Service, \\ Child and Adolescent Department, University Hospitals, Geneva, ' Department of Neuroradiology, University \\ Hospital of Geneva and University of Geneva, d Department of Neurosurgery, University Hospital of Geneva and \\ Faculty of Medicine, University of Geneva, ${ }^{e}$ Department of Neuropediatrics, Children's Hospital St. Gallen, \\ St. Gallen, Switzerland
}

Hemimegalencephaly is a congenital malformation characterized by a unilaterally enlarged and anatomically abnormal hemisphere, often associated with seizures. Patients with this syndrome are often responsive to functional hemispherotomy. Figure 1 is from a 3 -month-old girl who had been suffering from severe treatment-resistant epilepsy since birth, due to right hemimegalencephaly. After three disconnective neurosurgical procedures, the girl was free of clinical seizures. However, ictal activity over the abnormal hemisphere was still recorded 7 months after the last operation, but disappeared a year later (fig. 2). We conclude that an ipsilateral ictal pattern may be part of the postoperative EEG, without indicating incomplete disconnection.

\section{Acknowledgments}

The work was supported by the Swiss National Science Foundation (No. 140332, No. 122073 and No. 140338).

\section{Disclosure Statement}

The authors report no disclosures.

\section{References}

1 Flores-Sarnat L: Hemimegalencephaly: part 1. Genetic, clinical, and imaging aspects. J Child Neurol 2002;17:373-384.

-2 Di Rocco C, Iannelli A: Hemimegalencephaly and intractable epilepsy: complications of hemispherectomy and their correlations with the surgical technique. A report on 15 cases. Pediatr Neurosurg 2000;33:198207.

\section{KARGER}

Fax +41613061234

E-Mail karger@karger.ch

www.karger.com
(C) 2012 S. Karger AG, Basel

$0014-3022 / 12 / 0686-0358 \$ 38.00 / 0$

Accessible online at:

www.karger.com/ene
Laurent Sheybani

Neurology Clinic, University Hospital (HUG) and University of Geneva

4 , rue Gabrielle-Perret-Gentil

CH-1211 Genève (Switzerland)

E-Mail laurent.sheybani@unige.ch 
Fig. 1. Preoperative MRI (a) shows right hemimegalencephaly; ictal EEG (b) right, predominantly anterior activity.
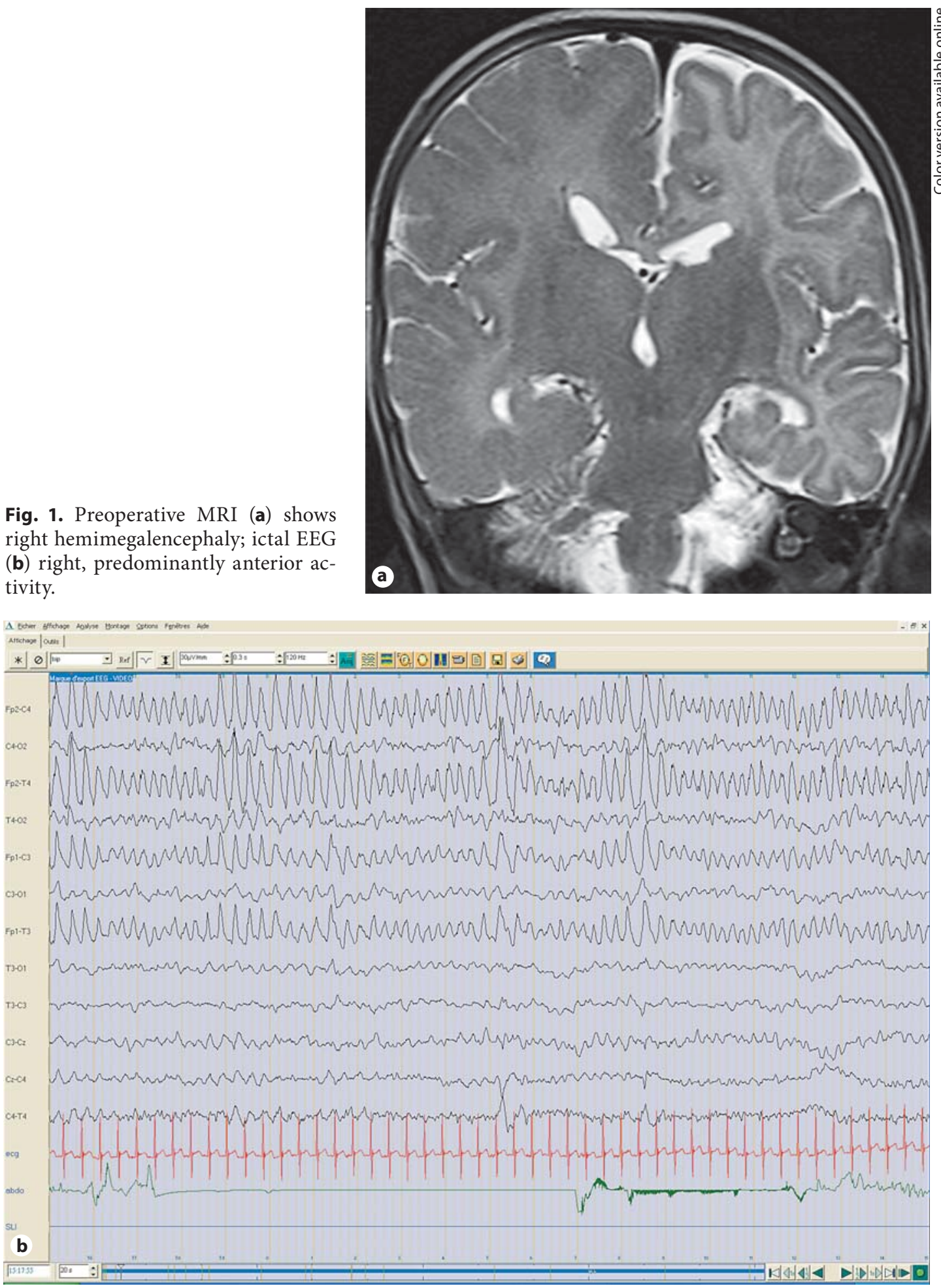

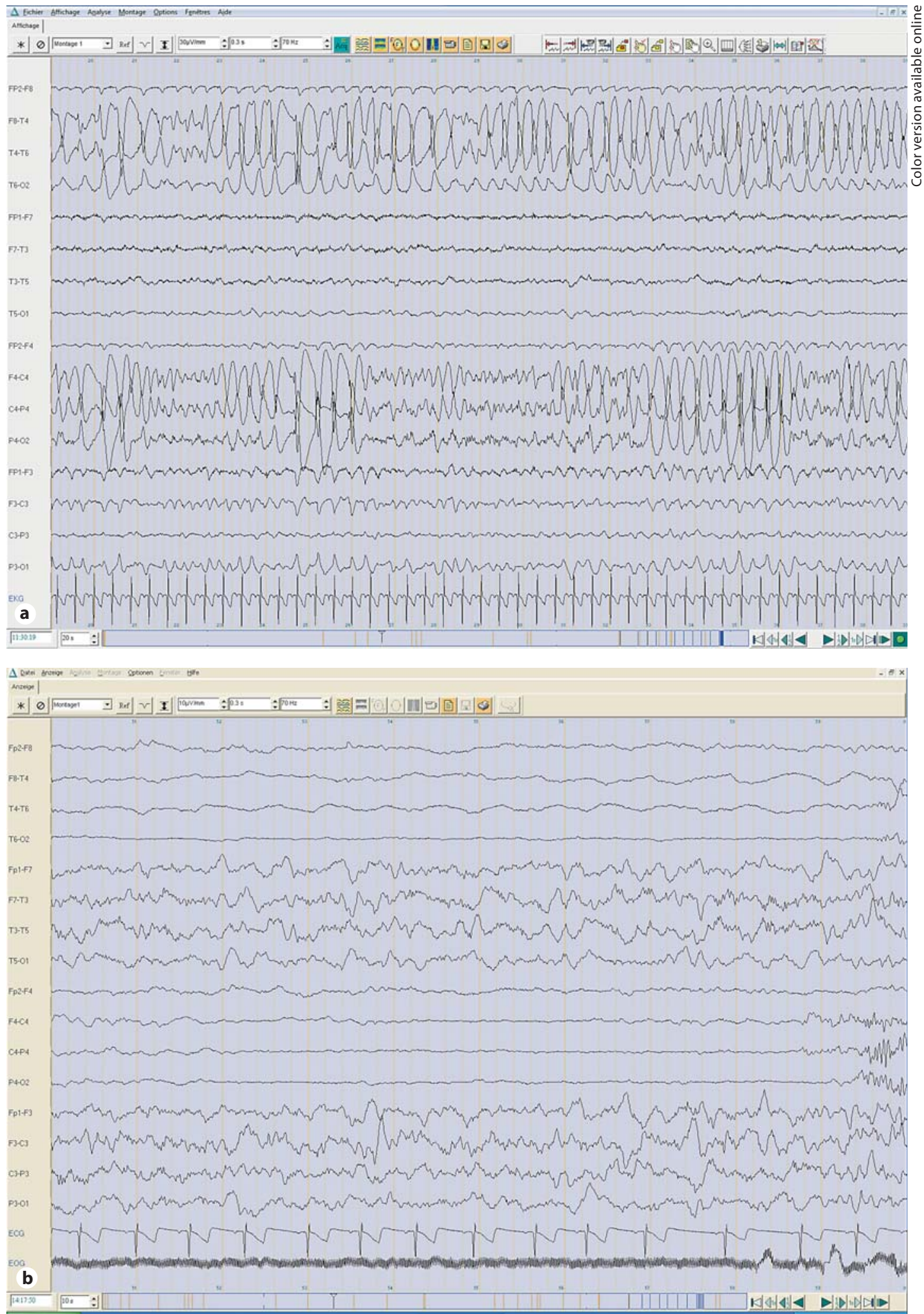

Fig. 2. Seven months after the third operation, EEG shows persistent ictal activity confined to the isolated hemisphere (a); a year later, only a decreased background activity with intermittent bursts of rapid rhythms was recorded (b). 